\title{
Hal İşletmelerinin İç Kontrol Sistemi ve Sektörel Sorunları: Edirne ve Çanakkale'de Bir Alan Araştırması
}

\section{Seda YAVUZASLAN SÖYLEMEZ ${ }^{1}$ İlknur ESKİN ${ }^{2}$}

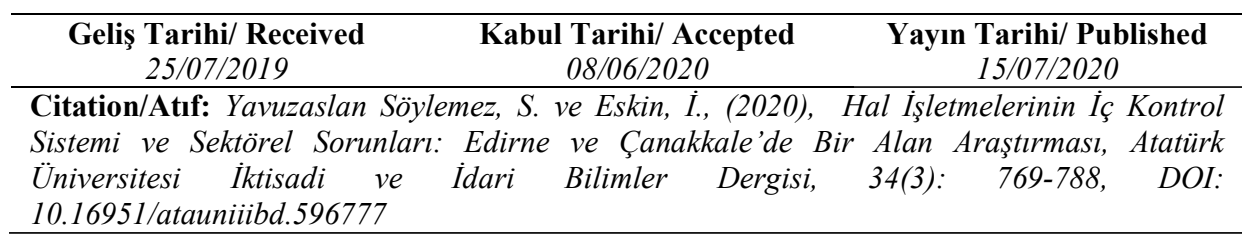

Öz: İç kontrol sistemi, işletme faaliyetlerinin etkenliğini ve verimliliğini, kârlılık hedeflerine ulaşmasını, varlıklarının korunmasını, finansal tabloların güvenirliğini sağlanmasını ve yasal düzenlemelere uyumunu sağlamaktadır. Ülke ekonomimizde önemli bir yere sahip olan tarım sektöründe pazarlama kanalı rolünü üstlenen ve tarımsal ürünleri üreticiden alıp ya doğrudan tüketiciye ya da toptancilar aracilığıla tüketiciye satan meyve ve sebze ticaretini yapan hal işletmelerinin iç kontrol yeterliliği sektörün dinamik bir yapı kazanması açısından çok önemlidir. Çalışmanın amacı Edirne ve Çanakkale ili meyve- sebze hallerindeki işletmelerin iç kontrol sistemlerinin test edilmesi ve hal işletmelerinin sorunlarının tespit edilmesidir. $\mathrm{Bu}$ amaç doğrultusunda anket ve yarı yapılandırılmış görüşme yöntemi uygulanarak, elde edilen bulgular değerlendirilmiştir. Çalışma sonucunda işletmelerde eğitim düzeyi arttıkça iç kontrol etkinliğinin arttığı, daha fazla personel çalıştıran işletmelerin iç kontrol puanının daha yüksek olduğu; şirket faaliyet sürelerine göre iç kontrol sistemi puanları arasında farklılık olmadı̆̆ı, sirketlerin hukuki yapılarına baktığımızda da sermaye şirketlerinin iç kontrol sistemi puanının daha yüksek olduğu belirlenmiştir. Yarı yapılandırışmış görüşme yöntemi ile de sektör içinde yaşanan sorunlar tespit edilerek, çözüm önerileri sunulmuştur

Anahtar Kelimeler: Sebze ve Meyve Hallerindeki İşletmeler, İç Kontrol Sistemi, Hal kayıt sistemi, Hal işletmelerinin sorunları.

\section{Internal Control System of Enterprises in Fruit Vegetable Sector and Sectoral Problems: A} Field Research in Edirne and Canakkale

Abstract : The internal control system ensures the effectiveness and efficiency of business operations, reaching profitability targets, protecting assets, ensuring the reliability of financial statements and compliance with legal regulations. The internal control adequacy of the enterprises, which take the role of a marketing channel in the agricultural sector, which has an important place in our country's economy, and trades fruits and vegetables that buy agricultural products from the producer and sell them either directly to the consumer or through the wholesalers, is very important for the sector to gain a dynamic structure. The aim of this study is to test the internal control system of enterprises in Edirne and Çanakkale province and to determine the problems of wholesale food

${ }^{I}$ Dr. Öğr. Üyesi, Çanakkale Onsekiz Mart Üniversitesi, Biga Meslek Yüksekokulu, Muhasebe ve Vergi Uygulamaları Bölümü, https://orcid.org/0000-0002-8392-3737

${ }^{2}$ Dr. Öğr. Üyesi, Trakya Üniversitesi, Uzunköprü Uygulamalı Bilimler Yüksekokulu, Muhasebe Bölümü, https://orcid.org/0000-0003-2306-7315 
Hal Işsletmelerinin İ̧̧ Kontrol Sistemi ve Sektörel Sorunları: Edirne ve Çanakkale'de Bir Alan Araştırması

markets. For this purpose, the findings obtained from the questionnaire and semi-structured interview method were evaluated. As a result of the study, as the level of education increases, the efficiency of internal control increases, and the enterprises employing more personnel have higher internal control scores; It is determined that there is no difference between the internal control system points according to the enterprises activity periods and when we look at the legal structures of the enterprises, the internal control system score of the capital companies is higher.With the semi-structured interview method, problems encountered in the sector were identified and solutions were offered.

Key Words: Enterprise in the vegetable and fruit sector, Internal Control System, wholesale registration system, Problems of wholesale food markets.

\section{EXTENDED SUMMARY}

\section{Research Problem:}

This study focuses on the internal control systems of the Edirne and Çanakkale fruit and vegetable enterprises and the problems of the Edirne and Çanakkale fruit and vegetable enterprises.

\section{Literature Review:}

The internationally accepted COSO (The Committee of Sponsoring Organizations of the Treadway Commission), "Internal Control - Integrated Framework" was used as the theoretical basis of the study. The COSO model is a model that includes risk-oriented and non-financial processes. This model allows us to evaluate the activities of the business with control environment, risk assessment, control activities, information \& communication and monitoring components

\section{Methodology:}

In the study, the mixed method was used where the questionnaire and semistructured interview method were used together. 105 vegetables and fruit trading companies registered with Edirne and Çanakkale Chamber of Commerce and Industry were determineted. These enterprises were made Interviews by appointment. In 2017, 42 businesses in Edirne and Keşanda, 35 businesses in Çanakkale were held both questionnaires and face to face interviews. However, some businesses did not answer the questions clearly and the data of 73 companies were evaluated. The questionnaire used for the first part of the study is a 3-point Likert Scale consisting of questions containing the determined variables and consists of two parts. The first part consists of the questions about the legal structures of the enterprises, their duration of operation, the number of personnel, their educational status and the markets in which they operate. In the second part, internal control effectiveness was tried to be measured with the 3point Likert scale and questions related to purchase, storage, management and accounting variables were prepared. The data obtained were analyzed with SPS 22 package program. In the second part of the study, the following questions were asked to the businesses operating as wholesalers: What are the factors that affect your choice of state broker or trader?, Why are corporate chain markets operating?, Can the registration system prevent informality ?, What are the 
troubles in the system ?, What ways do you buy vegetables and fruits from the producer?

\section{Results and Conclusions:}

The following results were achieved in the analysis of the data obtained by the survey method. it is seen that Internal control efficiency increases as the level of education increases in businesses, the internal control score of enterprises employing more personnel is higher, there is no difference between the internal control system scores according to the company activity periods and the capital companies' internal control system was more effective. In addition, it was determined that not enough attention has been paid to the principle of "separation of duties" in businesses, no documents are used in the management of processes other than legal documents such as invoices, dispatch notes, and an adequate system to prevent cheating and irregularities has not been established and the number of enterprises considering the waste rates is low. A significant part of the participants $(63 \%)$ stated that the new law does not prevent informality.

The following results were achieved in the evaluation of the data obtained through the semi-structured interview method:

- They stated that the new marketplace law prevented brokers from creating monopoly by stocking and they chose to work as a trader because the share of brokers did not exceed 8 percent of the sales price of the product.

-. They stated that with the new law, supermarkets could open businesses in marketplace and buy products directly from the manufacturer through this business and thereby reduce the costs of the supermarkets.

-. They stated that buying and selling of vegetables and fruitswithout logging into a wholesaler, the products were sold in the local markets without tags and there are not enough controls on the subject.

-. As the most important problem in the system, they stated that some businesses operating as wholesalers did not pay the price of the product they bought from the manufacturer within 5 days, nevertheless they were able to obtain the identification of the product and there was no sanction related to this.

- The participants stated that they bought vegetables and fruits directly from the field to distribute the risk and reduce costs or they got it after it was produced.

If state enterprises integrate the internationally accepted COSO internal control model into their systems, their activities will increase efficiently and efficiently. They should also evaluate their activities objectively.

Law No. 5957 on the "Regulation of the Trade of Vegetables and Fruits and Other Goods with Sufficient Supply and Demand Depth" came into force in 2010. With this Law, it is aimed to determine the standards of the fruit and vegetable trade and to bring wholesale markets and market places to a modern system. Although this law contains important regulations in order to provide economic and social benefits, problems remain due to the inefficient control mechanism in the system. In this context, informality can be tackled If the 
Hal Işsletmelerinin İ̧̧ Kontrol Sistemi ve Sektörel Sorunları: Edirne ve Çanakkale'de Bir Alan Araştırması

municipalities take joint liability and where the Ministry has established a more effective control system. If a control mechanism is created in this way, the companies who businesses in the wholesale market will be able to manage their processes more effectively.

\section{Giriş}

İç kontrol sistemi; işletme varlıkların korunması, hata ve hilelerin önlenmesi ve tespit edilmesi, finansal bilgilerin doğruluğunu ve güvenirliğini sağlanması ile işletme verimliğinin artıracak yöntem ve prosedürlerin oluşturulması, uygulanması ve test edilmesini kapsamaktadır. İşletmenin ölçeği ne boyutta olursa olsun hedeflerine ulaşması için bu sistem kurulmalı, geliştirilmeli ve test edilmelidir (Kızılboğa ve Özşahin,2013: 223).

İç kontrol sistemi bir işletmenin performans ve kârlllık hedeflerine ulaşmasına ve kaynaklarını etkin kullanmasına ve güvenilir finansal raporlama hazırlamasına yardımcı olur. İşletmenin kanunlara ve düzenlemelere uymasını ve dolayısıyla itibarına ve diğer özelliklerine zarar gelmesinin engellenmesine yardımcı olur (İbiş ve Çatıkkaş, 2012: 99). Son yıllarda yaşanan ekonomik bunalımlar ve krizlerden sonra zor durumda kalan işletmelerden dolayı iç kontrole verilen önem daha da artmıştır (Güney ve Sarı, 2015: 8).

İşletmelerin özellikleri farklı olması nedeniyle her işletmenin iç kontrolden beklentisi de farklı olmaktadır. İşletmelerin iç kontrol yapısının oluşturulmasında; işletmenin büyüklüğü, işletmenin mülkiyet yapısı, hukuki şekli, faaliyette bulunduğu sektör, kullanılan bilgi iletişim sistemi ve yasal düzenlemeler etkili olmaktadır (Şaşmaz ve Çiftçi, 2017: 113).

Çalışmanın diğer bölümlerinde sırasıyla iç kontrolle ilgili temel kavramlar ve toptancı hallerinin hukuksal yapısı, araştırmanın örneklemi, araştırmada elde edilen nicel ve nitel bulguların analizi açıklanmıştır. Sonuç bölümünde ise araştırmadan elde edilen bulgular değerlendirilmiştir.

\section{1.İ̧ Kontrol Kavramı}

\section{1. İç Kontrol İle İlgili Temel Kavramlar}

Kontrol kavramı, mevcut iş başarısının ölçülmesi ve bu başarının belirlenen amaçlara ne ölçüde ulaşıldığının tespit edilmesi olarak tanımlanmaktadır (Kızılboğa ve Özşahin,2013: 221) İşletme içinde var olan kontrolleri, işletme dışındaki denetimden ayırmak için iç kontrol kavramı kullanılmaktadır (Hatunoğlu vd,2012: 173).

İç kontrol, bir kurumun yönetim kurulu ve diğer personeller tarafindan etkilenen, kurumun operasyonel etkinliği, raporlama güvenirliği ve yasalara uyumuna dair makul güvence elde etmek amaciyla kurulan bir süreç olarak tanımlamaktadır (COSO, 2013: 3). Bu tanım, uluslararası standartları belirleyen tüm düzenleyici meslek otoritelerinin düzenlemelerinde ve birçok ülkenin yasalarında yer almaktadır (Gönen, 2009: 192).

ABD'de 1970'li yılların sonu ve 1980'li yılların başında hileli finansal rapor sayısındaki artışa bağl1, Hileli Finansal Raporlama Ulusal Komisyonu, iç 
kontrol çalışmalarının yürütülmesi amacıyla 1985 yılında COSO ‘yu (Committee of Sponsoring Organizations of The Treadway Commission) oluşturmuştur (Gönen, 2009: 192). COSO'nın amacı, kurumsal risk yönetimi, iç kontrol ve hileden caydırıcılık olmak üzere birbiriyle ilgili üç konuda düşünce liderliği sağlamaktır. COSO, iç kontrol rehberini (İç Kontrol-Bütünleşik Çerçeve) 1992 yılında yayınlamıştır. Bu rehber 2013 yılında tekrar gözden geçirilerek yayınlanmıştır (www.coso.org). 2000'li yıllarda ise ABD'de şirketlerinde yapılan usulsüzlüklerin ortaya çıkması denetim standartlarının tekrar ele alınmasına ve bazı düzenlemelerin yapılmasına neden olmuştur. 2002 yılında yürürlüğe giren Sarbanes- Oxley Yasası bu düzenlemelerin en önemlisidir. $\mathrm{Bu}$ yasanın amacı ABD'de halka açık şirketlerin finansal bilgilerin doğruluğunu ve güvenilirliğini sağlayarak, yatırımcıları korumaktır. Bunun için şirketin üst düzey yöneticilerine finansal raporlama sürecinde iç kontrol sistemini oluşturmada, uygulamada, etkinliğini ölçmede ve finansal raporları korumada sorumluluklar verilmiştir (Kazan ve Kazan, 2016: 255-256). Bu iki oluşum iç kontrolün uluslararası boyutta önem kazanmasında etkili olmuştur.

\section{2. İ Control Sistemi ve Bileşenleri}

İç kontrol sistemi, bir şirketin varlıklarını korumak, muhasebeye ve diğer faaliyetlere ilişkin bilgi ve raporların doğruluk ve güvenilirliğini sağlamak, işletmenin faaliyetlerinde etkinliği artırmak, işletme yönetimince belirlenen politikalara işletme faaliyetlerinin uygunluğunu saptamak için kullanılan tüm ölçü ve yöntemleri, hesap planının ve raporlama sisteminin kurulmasını, görev, yetki ve sorumlulukların belirlenmesini ve işletmenin organizasyon planını kapsamaktadır (İbiş ve Çatıkkaş, 2012: 98).

İç kontrol sistemi, birbiriyle uyumlu, birbirini destekleyen, önleyici, saptayıc1, yönlendirici ve telafi edici (tamamlayıcı) kontrol faaliyetleridir (Atmaca, 2012: 198). Bu kontrol faaliyetleri sayesinde işletme personeli neyi, nasıl yapacağını ve sorumluluklarını bilir. (Ömürbek ve Altay,2011:383).

İç kontrol sisteminin kurulmasında en çok tercih edilen model COSO modelidir. COSO modelinin en temel özelliği risk odaklı ve mali olmayan süreçleri de kapsamasıdır (Topçu, 2013: 10). Bu model beş bileşeni kapsayacak şekilde tasarlanmıştır. Bileşenler şunlardır (Akyel, 2010: 86, Gönen, 2009: 195200, Ceyhan ve Apan, 2014: 182-183, www.deloitte.com) :

Kontrol Ortamı: İşletmenin genelinde iç kontrolün yürütülmesine temel oluşturan standartlar, prosedürler ve süreçleri kapsayan; tutum, davranış, farkındalık, yeterlilik ve üslup gibi kavramları içeren, işletmenin iş yapma biçimini ifade eder.

Risk Değerlendirme: Kurumun hedeflerini gerçekleştirmesinin önündeki engel ve önemli riskleri tespit edip, analiz etme ve bu risklere uygun önlemler belirleme sürecidir.

Kontrol Faaliyetleri: Ticari faaliyet hedeflerinin gerçekleştirilmesini ve risk azaltma stratejilerinin yürütülmesini sağlamak amacıyla kullanılan politikalar, kurallar ve uygulamalardır. 
Hal Işsletmelerinin İ̧̧ Kontrol Sistemi ve Sektörel Sorunları: Edirne ve Çanakkale'de Bir Alan Araştırması

Bilgi ve İletissim: İç iç kontrol sistemi kurulması ve kurum hedeflerinin gerçekleştirilmesi için çalışanların sorumluluklarını yerine getirebilmeleri amacıyla bilgiler anında kaydedilmeli düzgün biçimde sınıflandırılmalıdır. İletişim ise; bilginin, gerek idare içinde yatay ve dikey olarak gerekse idare dışında uygun mekanizmalarla ilgili kişi, idare ve mercilere iletilmesini ve dönüşümünü ifade eder.

İzleme: İç kontrolün zaman içindeki performansının kalitesini değerleme sürecidir.

Çalışma, iç kontrol sistemi bileşenlerinden "kontrol ortamı" ile "kontrol faaliyetlerini” içermektedir. Bundan dolayı çalışmanın uygulama kısmı iç kontrol sisteminde iki bileşeni içeren değerlendirmeleri kapsamaktadır.

\section{Toptancı Hallerinin Hukuksal Yapısı}

Toptancı hallerinin temel kuruluş amacı, yaş meyve sebze pazarlamasını serbest rekabet sistemi içerisinde yürütmek ve üretici ile tüketici arasında malların akışını belli standartlar çerçevesinde gerçekleşmesini sağlamaktır (Çetin, 2009:23).Ülkemizde yaş meyve ve sebze pazarlamasında toptancı halleri ile ilgili yasal düzenlemeler, ilk defa 12 Eylül 1960 tarih ve 80 sayılı Toptancı Halleri Sureti İdaresi Hakkında Kanun ile düzenlenmiştir (www.tusiad.org.tr). Daha sonra 27 Haziran 1995 tarihli 552 sayılı Kanun Hükmünde Kararname ve 11 Haziran 1998 tarih ve 4367 sayılı Kanun Hükmünde Kararname ile yaş meyve ve sebze pazarlaması ile ilgili düzenlemeler yapılmıştır. 4367 sayılı yasa ile yaş meyve ve sebzeyi kayıt altına almak amaçlandığı için tüm yaş sebze ve meyvenin halden geçirilme zorunluluğu getirilmiştir (www.mevzuatdergisi.com). Bu yasal düzenlemelerin meyve ve sebze ticaretinde kayıt dışılığını önlemede yetersiz kaldığı görülmektedir. Örneğin; yıllara göre değişmekle birlikte, iç piyasaya sürülen meyve ve sebzenin sadece \%30'unun toptancı hallerinde işlem gördüğü, \%70'inin ise kayıt dışı olarak pazarlandığı belirtilmektedir (Adanacıoğlu ve Yercan, 2012:845). Bu nedenle yeni bir düzenlemeye ihtiyaç duyulmuş ve "5957 Sayılı Sebze ve Meyveler ile Yeterli Arz ve Talep Derinliği Bulunan Diğer Malların Ticaretinin Düzenlenmesi Hakkında Kanun" 2010 yılında yürürlüğe girmiştir. Kanun, sebze ve meyve ticaretinin standartlarını belirleyerek, toptancı halleri ile pazar yerlerinin çağdaş bir sisteme kavuşturmayı amaçlamaktadır. $\mathrm{Bu}$ Kanununun getirdiği en önemli düzenlemelerden birisi hal kayıt sistemidir. Hal kayıt sisteminin yapısı aşağıda açıklanmıştır.

\subsection{Toptanci Hali ve Hal Kaylt Sistemi}

Toptancı hali, belediyeler ile gerçek ve tüzel kişiler tarafından kurulan, sebze ve meyvenin toptan alım ve satımı ile kaydının yapıldığı yerdir. Buradaki işlemlerde iki taraf vardır. Birinci tarafta ürünü üreten çiftçi veya ürün sahibi tüccar, ikinci tarafta ise ürünü satın alan kişi veya ürünü satan komisyoncu vardır. Komisyoncu, ürünün toptan satışını kendi adına veya başkası adına komisyon esası üzerinden sağlayan meslek erbabıdır. Tüccar ise, ürünün toptan satışını kendi adına ve hesabına yapan meslek erbabıdır (5957 sayılı Kanun; madde 1-3). 
Toptancı halinde sebze ve meyve alım ve satım işlemlerinin kayıt altına alınması amacıyla hal kayıt sistemi oluşturulmuştur. Hal kayıt sistemi, toptancı hali içinde veya dışında işlem gören sebze ve meyvelere ilişkin bilgilerin elektronik ortamda tutulmasını, izlenmesini ve duyurulmasını; meslek mensupları ile ilgili bilgilerin kayıt altına alınmasını ve bunlara yönelik veri tabam oluşturulmasını sağlamayı amaçlamaktadır. Bu sistem sayesinde toptancı halleri arasında ortak bilgi paylaşımı ve iletişim sağlanmaktadır (Adanacıoğlu ve Yercan, 2012:847).

Hal kayıt sistemine sebze ve meyvenin üretildiği yerden veya ithal ediliyorsa gümrük kapısının bulunduğu yerden bu ürünler sevk edilmeden önce sebze ve meyvelerin alımı, satımı ve devrini yapan gerçek ve tüzel kişiler tarafindan bildirimde bulunulması gerekir. Toptanc1 hali olmayan yerlerde bildirimler Ticaret Bakanlığı'nın belirlediği hale yapılır. Yönetmeliğe göre;sebze ve meyve ihracatçıları, sebze ve meyve ithalatçıları, üretici örgütleri, komisyoncular, tüccarlar, market, manav, pazarcı ve diğer perakendeciler, üreticiden temin ettiği malları doğrudan kendi tüketiminde kullanan lokanta, otel, yemekhane, hastane ve yurt gibi kuruluşlar bildirimde bulunmak zorundadır (Hal Yönetmeliği, madde 40) .

Hal kayıt sistemine istenen bilgiler girilmesi sonucunda malın üretim yerini, cinsini, miktarını, hangi üretici/işletmeye ait olduğunu ve varsa sertifika bilgilerini içeren "künye ye ulaşılır. Toptan veya perakende mal satışında malların ya da ambalajların üzerinde künyenin bulundurulması zorunludur. Künye ile birlikte barkodlu etiket istenildiği durumda her iki belgede ürünün üzerinde yer alır ( www.hks.gov.tr).

Sebze ve meyveyi satın alan kişinin toptancı hallerinde veya dışında satış yapabilmesi için toptan satış bedeli üzerinden "hal rüsumu" ödemesi gerekmektedir. İthal edilen mallar ile fatura veya müstahsil makbuzu ile üreticilerden satın alınan mallardan; toptancı halinde satılanlardan yüzde bir, toptancı hali dışında satılanlardan yüzde iki oranında hal rüsumu alınır. Hal rüsumu, bildirim işleminin tamamlanmasıyla tahakkuk eder. Tahakkuk eden bu tutar TC. Gümrük ve Ticaret Bakanlığı'nın hal rüsumu hesabına yatırılır. Ürünün üretildiği bölgede hal yok ise rüsum tutarının tamamı tüketim bölgesindeki belediye halinin hesabına Bakanlık tarafindan yatırılır. Ĕger hem üretim hem de tüketim bölgesinde hal yok ise Bakanlık tarafından belirlenen belediyenin toptancı hali hesabına yatırılır. Bakanlığın havuzunda toplanan hal rüsumu, Bakanlık tarafından ilgili belediyelerin hesabına yatırılır. Belediye bu fonu toptancı halinin ihtiyaçlarını karşılamak için kullanır (5957 sayılı Kanun, madde $8)$.

\section{Uygulama}

\subsection{Araştırmanin Amacı}

Toptancı hallerindeki işletmelerin emek yoğun olması, çalışanların eğitim düzeyinin düşük olması, ürünlerin üretim yerinden tüketim yerlerine doğru ürün sevkiyatının olması, ürünlerin raf ömürlerinin kısa olması gibi nedenlerden dolayı 
Hal Işsletmelerinin İ̧̧ Kontrol Sistemi ve Sektörel Sorunları: Edirne ve Çanakkale'de Bir Alan Araştırması

hata ve hilelerin olması gerçektir. Araştırmanın amacı sebze ve meyve hallerinde tacir veya komisyoncu sıfatıyla yaş meyve sebze ticaretini yapan işletmelerin iç kontrol yeterliliğini tespit etmek ve bu işletmelerin sektörde yaşadığı sorunları belirlemektir.

Literatür taramasında sebze ve meyve hallerinde faaliyet gösteren işletmelerin iç kontrol yeterliliklerini tespit etmeye yönelik çalışmalara rastlanmamıştır. Bu çalışma hem literatüre katkı sağlamayı hem de sebze ve meyve hallerindeki işletmelerinin iç kontrol yeterlilik düzeylerini ve sektörün sorunlarını belirlemeyi amaçlamaktadır.

\subsection{Araştırmanin Yöntemi}

Araştırmanın amacı doğrultusunda anket ve yarı yapılandırılmış görüşme yönteminin bir arada kullanıldı̆̆ı, karma yöntem seçilmiştir. Karma yöntem araştırmaları, araştırmacının yaptığı araştırmada nitel ve nicel yöntem, yaklaşım ve kavramlarını birlikte kullanması olarak ifade edilebilir (Creswell, 2003).Araştırmacı nitel ve nicel verileri ayrı çalışmalarda ister sıralı bir şekilde, isterse de eşzamanlı olarak toplar. Çoklu çalışma olarak ifade edilen bu araştırmalarda nitel veriler ve nicel veriler ayrı bağımsız birer çalışma olarak görülüp ayrı ayrı rapor edilmekte, ancak araştırılan proje genel olarak karma yöntem araştırması olarak adlandırılmaktadır (Creswell, 2006). Araştırmanın birinci kısmı için kullanılan anket, belirlenen değişkenleri içeren sorulardan oluşan 3'lü Likert Ölçeğinde olup, iki bölümden oluşmaktadır. Birinci bölümde işletmelerin hukuki yapıları, faaliyet süreleri, personel sayıları, eğitim durumları, faaliyet gösterdikleri pazarlara yönelik sorulardan oluşmaktadır(Ömürbek ve Altay,2011:388).İkinci bölümde 3'lü likert ölçeği ile içkontrol etkinliğini ölçmeye yönelik kullanılan satın alma, depolama, yönetim ve muhasebe değişkenlerine ait sorular yer almaktadır. Bu sorulardan elde edilen veriler SPS 22 paket programına aktarılarak, elde edilen bulgular analiz edilmiştir. Araştırmanın ikinci kısmı için kullanılan yarı yapılandırılmış görüşme yöntemi ile toptancı halinde faaliyet gösteren işletmelere belirlenen ortak sorular sorulmuş ve onlardan alınan cevaplar değerlendirilmiştir.

\subsection{Araştırmanın Evreni, Örneklemi ve Veri Toplam Şekli}

Araştırmanın evrenini Çanakkale ve Edirne illerinde sebze ve meyve hallerindeki işletmeler oluşturmaktadır. $\mathrm{Bu}$ illerinin seçilmesinin nedeni; Çanakkale ilinin hem üretici hem tüketici boyutunun olması (domates, şeftali, kiraz gibi ürünlerde üretici; turunçgillerde tüketici), Edirne ilinin tüketici boyutunda olmasidir.

Edirne ile Çanakkale Ticaret ve Sanayi Odalarına kayıtlı 105 sebze meyve ticareti yapan işletme tespit edilmiştir. Çanakkale, Edirne ili ile Keşan ilçe hal müdürlüklerinden halde aktif olarak sebze ve meyve ticareti yapan işletmelerin bilgilerine ulaşılmıştır. Bu işletmelerden randevu talep edilerek, görüşme talep edilmiştir. 2017 y1lında Edirne ili ve Keşan ilçesinde toplam 42 işletmeye, Çanakkale ilinde 35 işletmeye hem anket uygulanmış, hem de yüz yüze sorular 
iletilmiştir. $\mathrm{Bu}$ araştırmadan çeşitli sınırlılıklardan dolayı toplam 73 tanesi değerlendirmeye alınmıştır. Bunun en önemli nedeni geleneksel yönetim anlayışııı benimseyen yöneticilerin sorulara net cevap vermemelerinden kaynaklanmaktadır.

\subsection{Anket Yönteminden Elde Edilen Verilerin Analizi}

İç kontrol sisteminin etkinliğinin ölçülmesine yönelik 26 sorudan oluşan anketin güvenilirlik katsayısı Cronbach'salfha değeri \% 79,4 olarak bulunmuştur. Güvenilirlik katsayısının \%70'ten büyük olması istenir ve katsayı 1'e yaklaştıkça güvenilirlik yükselir (Özdemir 2008, 291). Cronbach's Alpha katsayısı 0,7'den büyük olduğu için ankette kullandığımız ölçeğimizin güvenilir olduğu anlamına gelmektedir.

3.5. Araştırmanın İ̧ Kontrol Etkinliği ile ilgili Hipotezler, Yapılan Analizler ve Elde Edilen Bulgular

Araştırmanın anket verileri ile iç kontrol etkinliğinin değerlendirilmesi yapılmıştır. İç kontrol etkinliği için kurulan hipotezler, iç kontrol sistemi kontrol ortamının işletme sahiplerinin eğitim durumu, işletmede çalışan personel sayısı, işletmenin faaliyet süresi, işletmenin hukuki yapısı arasında anlamlı farklılık gösterip göstermediğini test etmeye yöneliktir. Araştırmanın hipotezlerinin analizinde ve araştırmada önce demografik özelliklerin tespit kısmında frekans tabloları kullanılmış, iç kontrol puanı ve diğer sayısal değişkenlerin incelenmesinde açıklayıcı istatistikler olan mod, medyan, ortanca ve varyans kullanılmışır .Hipotezlerin testinde ise normallik varsayımları ve gruplar arası varyans homojenlikleri kontrol edilmiş ve duruma göre parametrik ve parametrik olmayan testler tercih edilmiştir. Parametrik testlerden bağımsız örneklem t-testi ve anova kullanılırken parametrik olmayan testlerden ise Kruskal Wallis testi kullanılmıştır.

Araştırmada kullanılan ankette iç kontrol sisteminin etkinliğinin tespiti için yer alan 26 ifade, iç kontrol sisteminin kontrol ortamına ilişkin olarak ele alınan 4 boyut için düzenlenmiştir. Bu boyutlar satın alma, depolama, yönetim ve muhasebedir. Ankette katılımcılara yöneltilen satın alma, depolama, yönetim ve muhasebe değişkenleri ile ilgili firmaların iç kontrollerini ölçümleyen toplam 26 adet 3'lü likert tarzındaki sorularla iç kontrol puanı hesaplanmıştır. Burada sorularda Hayır=1, Kısmen=2 ve Evet $=3$ şeklinde puanlanmıştır. Buna göre ölçeğin alabileceği en düşük puan 26 iken en yüksek puan $78^{\prime}$ dir. Yine 26-43 puan arası yetersiz iç kontrol, 44-61 puan arası Orta seviye iç kontrol ve 62-78 puan arası ise Yeterli iç kontrol mevcut anlamı taşımaktadır. Buna göre ankete katılan firmaların \%6,8'inde yetersiz iç kontrol, \%63'ünde orta seviyede iç kontrol ve \%30,1'inde ise yeterli seviyede iç kontrol olduğu sonucuna ulaşılmıştır (Tablo: 1). 
Hal İşletmelerinin İç Kontrol Sistemi ve Sektörel Sorunları: Edirne ve Çanakkale'de Bir Alan Araştırması

Tablo 1: Gruplanmış İ̧̧ Kontrol Puanlarının Dağılımı

\begin{tabular}{|l|c|c|c|c|}
\hline Detay & Frekans & $\%$ & Geçerli (\%) & Birikimli (\%) \\
\hline Yetersiz I.K. & 5 & 6.8 & 6.8 & 6.8 \\
\hline Orta Seviye I.K. & 46 & 63.0 & 63.0 & 69.9 \\
\hline Yeterli I. K. & 22 & 30.1 & 30.1 & 100.0 \\
\hline Toplam & 73 & 100.0 & 100.0 & \\
\hline
\end{tabular}

İşletmelerin iç kontrol puanlarının en düşük aldığı değer 38 iken en yüksek aldığ 1 değer ise 76 'dır. Ayrıca firmaların ortalama iç kontrol puanı 56 olarak bulunmuştur. Standart sapma 9.7 olarak bulunmuştur ( Tablo 2 ve Tablo 3).

Tablo 2: Tanımlayıcı Istatistikler

\begin{tabular}{|l|l|l|l|l|l|l|}
\hline & N & Minimum & Maksimum & Ortalama & Std Sapma & Varyans \\
\hline Satinalmapuan & 73 & 5.00 & 15.00 & 9.7671 & 2.21435 & 4.903 \\
\hline Depolamapuan & 73 & 8.00 & 18.00 & 13.6027 & 3.14351 & 9.882 \\
\hline Yönetimpuan & 73 & 5.00 & 15.00 & 9.3288 & 2.95360 & 8.724 \\
\hline Muhasebepuan & 73 & 16.00 & 30.00 & 23.2740 & 4.03547 & 16.285 \\
\hline Toplam & 73 & & & & & \\
\hline
\end{tabular}

Tablo 3: Açıklayıcı İstatistikler

\begin{tabular}{|l|c|c|c|c|c|}
\hline \multicolumn{2}{|l|}{} & Minimum & Maksimum & Ortalama & Std. Sapma \\
\hline İç kontrol puan1 & 73 & 38 & 76.0 & 56.0 & 9.7 \\
\hline
\end{tabular}

Kontrol Ortamına İlişkin Boyutların Frekans Analizi

Araştırmada yapılan ankette yer alan ve iç kontrolün kontrol ortamına ilişkin olarak ele alınmış, dört boyutta (satınalma, depolama, yönetim, muhasebe) yer alan soruların frekans dağılımı tablo 3'de yer almaktadır. Tablodaki veriler doğrultusunda aşağıdaki sonuçlara ulaşılmıştır.

İşletmelerin \% 56'sı satın alma işlemlerini aynı kişi tarafindan yürütüyor. İşletmelerin \% 89'u satın alma sürecinde yazılı metin kullanmıyor. Katılımcilar $\% 57,5^{\prime}$ i satın alma işleminde fiyatın etkisi olduğunu belirtmiştir. İşletmelerin \% 57,5'i sevkiyat sürecini yöneten ayrı bir personel görevlendirmiyor. Fire oranlarını hesaplayan işletmeler ise katılımcıların \% 45'ini oluşturuyor. İşletmelerin \% 75,3'ü görev tanımlarını yazılı olarak personeline bildirmiyor. İşletmelerin \%64'ü hedeflerini personelle paylaşmıyor. İşletmelerin \% 57'si süreçlerde ayrı personel çalıştırmıyor. Yeni hal yasasının kayıt dışılığı engellemediğini düşünen katıllımcılar ise \% 63 'dür. İşletmelerin $\% 57,5^{\prime} \mathrm{i}$ hile veusulsüzlükleri önleyen kontrol mekanizmasına sahip olmadığını bildirmiştir. İşletmelerin \% 53'ü yasal zorunluluk dışında süreçleri takip etmek amacıyla evrak kullanmamaktadır. İşletmelerin $\% 41^{\prime} \mathrm{i}$ ön muhasebe işlemlerini 
yapmadığını belirtmiştir. Süreçle ilgili bu olumsuzluklara rağmen, katılımcılarön muhasebe işlemleri ile hal programına girilen veriler arasında fark olmadığını belirtmiştir. Sonuç olarak; personele yazılı görev tanımlarının verilmemesi, aynı kişinin birden fazla işi yürütmesi "görevler ayrılığı" ilkesinin dikkate alınmadığını göstermektedir. İşletme süreçlerin yönetiminde yasal evrak dışında evrak kullanılmaması, hile ve usulsüzlükleri engelleyecek mekanizmalarının olmaması, fire oranlarının dikkate alınmaması iç kontrol sisteminde sorunlar olduğunu göstermektedir. Ayrıca yeni hal yasasının kayıt dışılığı engellemediğini düşünenlerin yüksek oranda olması, sistem olan güvensizliği ortaya koymaktadır.

Tablo 3: İç Kontrol Sisteminin Etkinliğini Ölçmeye Yönelik Sorulan Soruların Frekans Analizi Sonuçları

\begin{tabular}{|c|c|c|c|}
\hline SATINAINCA & Hayır & Evet & Rismen \\
\hline Satın alma işleminde ayn bir kiģiye yetki veriliyor mu? & 41 & 30 & 2 \\
\hline Grinlikhaftaldk.aylik satın alma planlaması yapılıyor mu? & 30 & 39 & 4 \\
\hline Satın alma iģleminde onceli ginizi talep mi belirliyor? & 6 & 64 & 3 \\
\hline Satın alma işleminde ónceli ginizi fiyat ma belirliyor? & 42 & 27 & 4 \\
\hline Satun alma sürecinizi gobsteren yanli metin var mu? & 65 & 6 & 2 \\
\hline Depolama & Hayır & Evet & K.1smen \\
\hline Mallarin tesellum kontroli yapnliyor mu? (fixat,mjlktarkalite) & 13 & 58 & 2 \\
\hline Mallann depolanmasi ve sevkiyatında evrak sisteminiz var mi? & 21 & 46 & 6 \\
\hline MGinimum ve maks imum stok miktannızı dikkate alıyor musunuz? & 20 & $5 \mathrm{I}$ & 2 \\
\hline Envanter saymm yapiyor musunuz ?(ginlijk haftaldk.aylik) & 22 & 46 & 5 \\
\hline Mallann sevkiyatunda sevkiyat sürecini yöneten bą̧ka bir personel górevlendirilmią mi? & 42 & 30 & I \\
\hline Fire oranların zl belirli zaman diliminde hesaplayı, muhasebe birimine bilgi veriyor musunuz? & 33 & 39 & 1 \\
\hline Yonetim & Hayır & Evet & K1smen \\
\hline Işletme hedefleri belirlenip personele bilgi veriliyor mu? & $4 ?$ & 26 & 0 \\
\hline Personelin görevleri yazili olarak bildiriliyor mu? & 55 & 18 & 0 \\
\hline Personele yetki ve sorumluk egit bir şelkilde mi veriliyor? & 36 & 34 & 3 \\
\hline Hal program süreçlerin kontrolunde etkili mi? & 23 & 47 & 3 \\
\hline Süreçlerin her agamasında ays bir pers onele yetici verildi mi? & 42 & 29 & 2 \\
\hline Mahasebe & Hayır & Evet & K1smen \\
\hline Iģletmede ơn muhasebe iģlemleri yapiliyor mu? & 30 & 43 & 0 \\
\hline Işletmede ön muhasebe işlemleriyle hal pro gramuna girilen veriler aynı mu? & 9 & 61 & 3 \\
\hline Nakit digında tahsilat veya ódeme yapıldığnda takip ediliyor mu? & 4 & 67 & 2 \\
\hline Mal alış ve satı̧̧lar yasal belggeye mi dayalı? & 2 & 69 & 2 \\
\hline Mal alıg ve satı miktar ve tutarlan yasal belgelerle aym $\mathrm{mn}$ ? & 9 & 59 & 5 \\
\hline Hile ve usulstizluikleri onleyen kontrol mekanizmaniz var mi? & 42 & 29 & 2 \\
\hline Yasal zorunhuluklar dığmda (fanıra, isaliye gibi) surecin takib inde kullandiǧnız evraklar var ma? & 39 & 33 & 1 \\
\hline Yeni Hal Yasası kayıt dignlliğ onluyor mu? & 46 & 24 & 3 \\
\hline Nakit akıg̨nızı belírliyor musunuz? (haftalık, aylık) & 12 & 51 & 10 \\
\hline Harcamalannızı kontrol edecek sisteminiz var mu? & 38 & 34 & 1 \\
\hline
\end{tabular}

\subsection{Hipotezlerin Testi}

Araştırmanın hipotezleri iç kontrol sistemi kontrol ortamının işletme sahiplerinin eğitim durumu, işletmede çalışan personel sayısı, işletmenin faaliyet süresi, işletmenin hukuki yapısı arasında anlamlı farklılık gösterip göstermediğini test etmeye yöneliktir. Hipotezler aşağıdaki gibi oluşturulmuştur. 
Hal İşletmelerinin İç Kontrol Sistemi ve Sektörel Sorunları: Edirne ve Çanakkale'de Bir Alan Araştırması

H1: Eğitim durumuna göre iç kontrol sistemi puanı değişiklik gösterir mi?

H2: Personel sayısına göre iç kontrol sistemi puanı değişiklik gösterir mi?

H3: İşletmenin faaliyet süresine göre iç kontrol sistemi puanı değişiklik gösterir mi?

H 4: İşletmenin hukuki yapısı iç kontrol sistemi puanı değişiklik gösterir mi?

İç kontrol sistemi puanlarının dağılımı normal dağılıma uymaktadır. Ayrıca merkezi limit teoremi gereğince örnek çapımız 35' in üzerinde olduğundan normallik varsayımı altında hipotezler test edilmiştir. Hipotez testleri için önce ankete katılanların demografik özellikleri değerlendirilmiştir.

3.7. Ankete Katılanların Demografik Ö̈zellikleri

$\mathrm{Bu}$ bölümde işletmelerin çalıştığı bölge, hukuki yapısı, faaliyet süresi, işletme sahiplerinin eğitim durumu ve işletmelerde çalışan personel sayısı incelenmiştir. Anketin yapıldığı bölgelere göre Tablo 4'ü incelediğimizde; anketin \%30,1'i Keşan, \%21,9'u Edirne merkez ve \%47,9'u Çanakkale merkez ve Bayramiç bölgesinde yapılmıştır.

Tablo 4: Anketin Yapıldı $\breve{g}$ Bölge

\begin{tabular}{|l|l|l|l|l|l|}
\hline \multicolumn{2}{|c|}{} & Frekans & $(\%)$ & Geçerli (\%) & Birikimli(\%) \\
\hline \multirow{2}{*}{ N } & Keşan & 22 & 30.1 & 30.1 & 30.1 \\
\cline { 2 - 6 } & Edirne & 16 & 21.9 & 21.9 & 52.1 \\
\cline { 2 - 6 } & Bayramic.C.kale & 35 & 47.9 & 47.9 & 100.0 \\
\cline { 2 - 6 } & Total & 73 & 100.0 & 100.0 & \\
\hline
\end{tabular}

Araştırmaya katılan bireylerin \%27.4'ü ilk-ortaokul, \%47,9'ü Lise,\%2.7'si yüksekokul ve \%20.5'i üniversite mezunudur (Tablo 5).

Tablo 5: Ankete Katılanların Ĕ̈itim Durumu

\begin{tabular}{|c|c|c|c|c|c|}
\hline \multicolumn{2}{|c|}{ Detay } & Frekans(N) & Yüzde(\%) & Geçerli (\%) & Birikimli(\%) \\
\hline \multirow[t]{4}{*}{$\mathrm{N}$} & illk-orta & 20 & 27.4 & 27.4 & 27.4 \\
\hline & Lise & 35 & 47.9 & 47.9 & 75.3 \\
\hline & Yüksekokul & 2 & 2.7 & 2.7 & 78.1 \\
\hline & Üniversite & 15 & 20.5 & 20.5 & 98.630137 \\
\hline
\end{tabular}

Araştırmaya katılan işletmelerin çalıştırdıkları personel sayıları şu şekildedir; işletmelerin \%83.3'ü 1-10 kişi, \%12.3'ü 11-50 kişi ve \%1.4'ü ise 51 kişi ve üstü personel çalıştırmaktadır (Tablo 6). 
Tablo 6: Ankete Katılan Hal İşletmelerinde Çalışan Personel Sayısı

\begin{tabular}{|l|l|l|l|l|l|}
\hline \multicolumn{2}{|l|}{ Detay } & Frekans & Yüzde(\%) & Geçerli (\%) & Birikimli (\%) \\
\hline \multirow{2}{*}{ N } & $-1-10$ Kişi & 63 & 86.3 & 86.3 & 86.3 \\
\cline { 2 - 6 } & $.11-50$ Kişi & 9 & 12.3 & 12.3 & 98.6 \\
\hline .51 kişi ve üstui & 1 & 1.4 & 1.4 & 100.0 \\
\hline
\end{tabular}

Araştırmaya katılan işletmelerin \%27.4'ünün faaliyet süresi 1-5 Y1l ;\%20.5'i 6-10 y1l; \%9.6's1 11-15 y11;\%41.1'i 16 yıldır faaliyet göstermektedir (Tablo 7).

Tablo7: Ankete Katılan Hal İsletmelerinin Faaliyet Süresi

\begin{tabular}{|c|c|c|c|c|c|}
\hline \multicolumn{2}{|c|}{ Detay } & Frekans & Yüzde(\%) & Geçerli (\%) & Birikimli (\%) \\
\hline \multirow[t]{4}{*}{$\mathrm{N}$} & $-1-5$ yil & 20 & 27.4 & 27.8 & 27.8 \\
\hline & .6-10 Y11 & 15 & 20.5 & 20.8 & 48.6 \\
\hline & $.11-15$ Y11 & 7 & 9.6 & 9.7 & 58.3 \\
\hline & .16 y1l ve üstü & 30 & 41.1 & 41.7 & 100 \\
\hline
\end{tabular}

Araştırmaya katılan işletmelerin \%27.4'ü Limited şirket, \%2.7'si Anonim şirket ve \%69.9'u ise diğer şirket türlerindendir (Tablo 8).

Tablo 8: Ankete Katılan Hal Işsletmelerinin Hukuki Yapıları

\begin{tabular}{|l|l|l|l|l|l|}
\hline \multicolumn{2}{|l|}{ Detay } & Frekans & Yüzde(\%) & Geçerli (\%) & Birikimli (\%) \\
\hline \multirow{4}{*}{ N } & LTD_ŞTí. & 20 & 27.4 & 27.4 & 27.4 \\
\cline { 2 - 6 } & A.Ş- & 2 & 2.7 & 2.7 & 30.1 \\
\cline { 2 - 6 } & Diğer & 51 & 69.9 & 69.9 & 100.0 \\
\cline { 2 - 6 } & Toplam & 73 & 100.0 & 100.0 & \\
\hline
\end{tabular}

Ĕ̈itim Durumu hipotez testi;

H0: İç kontrol sistemi puanları eğitim düzeylerine göre farkl11ık göstermez.

H1: İç kontrol sistemi puanlarının en az biri eğitim düzeylerine göre farkl11ık gösterir.

Tablo 9: Varyans Homojenliği Testi

\begin{tabular}{|l|l|l|l|}
\hline İckontrolpuan1 & & & \\
\hline LeveneStatistic & df1 & df2 & Sig. \\
\hline 3.124 & 3 & 68 & .031 \\
\hline
\end{tabular}

Levene testinin sonucuna göre gruplar arası varyans homojenliği varsayımı sağlanmamaktadır. Bu yüzden parametrik olmayan test tekniklerinden Kruskal Wallis testi kullanılmıştır. Ama önce homojen olmayan dağılım olduğu için post hoc testi yapılmış ve farklılığın neden kaynaklandığı tespit edilmiştir. 
Hal İşletmelerinin İç Kontrol Sistemi ve Sektörel Sorunları: Edirne ve Çanakkale'de Bir Alan Araştırması

Tablo 10. Post Hoc Testi (Çoklu Karşılaş̧tırmalar)

\begin{tabular}{|c|c|c|c|c|c|c|}
\hline \multicolumn{7}{|c|}{ DependentVariable: } \\
\hline \multicolumn{7}{|l|}{ Tambane. } \\
\hline \multirow{2}{*}{\multicolumn{2}{|c|}{ (I) Eğitim Durumunuz }} & \multirow{2}{*}{$\begin{array}{l}\text { MeanDifference } \\
\text { (I-J) }\end{array}$} & \multirow{2}{*}{$\begin{array}{l}\text { Std. } \\
\text { Error. }\end{array}$} & \multirow[b]{2}{*}{ Sig. } & \multicolumn{2}{|c|}{$95 \%$ ConfidenceInteryal } \\
\hline & & & & & IowerBound & UpperBound \\
\hline \multirow[t]{3}{*}{ Illk-orta } & Lise & $-3,27857$ & 2,15759 &, 580 & $-9,1797$ & 2,6226 \\
\hline & Yüksekokul & 4,75000 & 2,44721 & .695 & $-17,5557$ & 27,0557 \\
\hline & Üniversite & $-12,05000^{-}$ & 2,66552 &, 001 & $-19,6812$ & $-4,4188$ \\
\hline \multirow[t]{3}{*}{ Lise } & Illk-orta & 3,27857 & 2,15759 & .580 & $-2,6226$ & 9,1797 \\
\hline & Yüksekokul & 8,02857 & 2,58193 & .309 & $-9,6045$ & 25,6616 \\
\hline & Üniversite & $-8,77143^{\circ}$ & 2,78972 &, 023 & $-16,6437$ &,- 8992 \\
\hline \multirow[t]{3}{*}{ Yüksekokul } & Illk-orta & $-4,75000$ & 2,44721 &, 695 & $-27,0557$ & 17,5557 \\
\hline & Lise & $-8,02857$ & 2,58193 &, 309 & $-25,6616$ & 9,6045 \\
\hline & Üniversite & $-16,80000^{\circ}$ & 3,01930 & .019 & $-30,0004$ & $-3,5996$ \\
\hline \multirow[t]{3}{*}{ Üniversite } & Illk-orta & $12,05000^{-}$ & 2,66552 &, 001 & 4,4188 & 19,6812 \\
\hline & Lise & $8,77143^{-}$ & 2,78972 &, 023 &, 8992 & 16,6437 \\
\hline & Yüksekokul & $16,80000^{-}$ & 3,01930 &, 019 & 3,5996 & 30,0004 \\
\hline
\end{tabular}

Post hoc testinin sonucunda $\mathrm{p}$ değeri 0,05 'den küçük olan ikili gruplar arasında farklılık söz konusudur. Çalışmamızda da ilk-ortaokul ile üniversite eğitim seviyeleri, lise ile üniversite eğitim seviyesi, yüksekokul ile üniversite eğitim seviyeleri arasında farklılık söz konusudur. Tablo 10 'da görüldüğü üzere üniversite eğitim seviyesi diğer bütün eğitim seviyeleri ile farkl1lık göstermektedir. Diğer eğitim seviyeleri arasında farkl1lık yoktur.

Tablo 11: Kruskal Wallis Testi

\begin{tabular}{|c|c|c|c|}
\hline \multicolumn{4}{|l|}{ Ranks } \\
\hline \multicolumn{2}{|c|}{ Eğitim Durumunuz } & $\mathbf{N}$ & MeanRank \\
\hline \multirow[t]{5}{*}{ İç kontrol puanı } & Ilk-orta & 20 & 28.05 \\
\hline & Lise & 35 & 35.27 \\
\hline & Yüksekokul & 2 & 15.50 \\
\hline & Universite & 15 & 53.43 \\
\hline & Total & 72 & \\
\hline \multicolumn{4}{|l|}{ Test Statisticsab } \\
\hline & \multicolumn{3}{|l|}{ Ickontrolpuanı } \\
\hline Chi-Square & \multicolumn{3}{|l|}{15.242} \\
\hline Df & \multicolumn{3}{|l|}{3} \\
\hline Asymp. Sig. & \multicolumn{3}{|l|}{.002} \\
\hline \multicolumn{4}{|c|}{ a. Kruska1 Wallis Test } \\
\hline
\end{tabular}


p-değeri $0,002<0,05$ olduğundan H0 hipotezi reddedilmiştir. Yani eğitim düzeylerine göre iç kontrol sistemi puanları farklılık göstermektedir. Bu sonuca göre, araştırmamızdaki işletmelerde eğitim düzeyi arttıkça iç kontrol etkinliği artmaktadır.

Personel Say1s1 Hipotez testi

H0: Personel sayısı gruplarına göre iç kontrol sistemi puanları arasında fark yoktur.

H1: Personel sayısı gruplarının en az biri iç kontrol sistemi puanı bakımından farklıdır.

Yapmış olduğumuz t-testi sonucunda grup varyanslarının homojen olduğunu sonucuna ulaşılmıştır. Buna göre p-değeri $0,022<0,05$ olduğundan H0 hipotezi reddedilir. Yani Personel sayısı grupları arasında iç kontrol sistemi puanı açısından farklılık vardır. İşletmesinde daha fazla personel çalışan işletmelerin iç kontrol sistemi puanının daha yüksek olduğu görülmektedir.

Tablo 12: $t$ testi

\begin{tabular}{|c|c|c|c|c|c|}
\hline \multicolumn{6}{|c|}{ Group Statistics } \\
\hline $\begin{array}{l}\text { Şirkette çalışan } \\
\text { sayınız }\end{array}$ & personel & $\mathrm{N}$ & Mean & $\begin{array}{c}\text { Std. } \\
\text { Deviation }\end{array}$ & $\begin{array}{l}\text { Std. } \\
\text { Error } \\
\text { Mean }\end{array}$ \\
\hline \multirow[t]{2}{*}{ ickontrolpuan } & $.1-10$ Kişi & 63 & 54.8254 & 9.31101 & 1.17308 \\
\hline & $\begin{array}{l}.11-50 \\
\text { Kişi }\end{array}$ & 9 & 62.6667 & 9.98749 & 3.32916 \\
\hline
\end{tabular}

\begin{tabular}{|c|c|c|c|c|c|c|c|c|c|c|}
\hline \multicolumn{11}{|c|}{ Independent Samples Test } \\
\hline & & $\begin{array}{l}\text { Levene's } \\
\text { Equal } \\
\text { Varia }\end{array}$ & $\begin{array}{l}\text { est for } \\
\text { of } \\
\text { ces }\end{array}$ & \multicolumn{7}{|c|}{ t-test for Equality of Means } \\
\hline & & \multirow[b]{2}{*}{$\mathrm{F}$} & \multirow[b]{2}{*}{ Sig. } & \multirow[b]{2}{*}{$\mathrm{t}$} & \multirow[b]{2}{*}{ df } & \multirow{2}{*}{$\begin{array}{l}\text { Sig. (2- } \\
\text { tailed) }\end{array}$} & \multirow{2}{*}{$\begin{array}{c}\text { Mean } \\
\text { Differenoe }\end{array}$} & \multirow{2}{*}{$\begin{array}{l}\text { Std. Error } \\
\text { Differenos }\end{array}$} & \multicolumn{2}{|c|}{$\begin{array}{l}95 \% \text { Confidence } \\
\text { Interval of the } \\
\text { Difference }\end{array}$} \\
\hline & & & & & & & & & Lower & Upper \\
\hline ickontrolpuanı & $\begin{array}{l}\text { Equal } \\
\text { variances } \\
\text { assumed }\end{array}$ & .376 & .542 & -2.343 & 70 & .022 & -7.84127 & 3.34639 & -114.51544 & -1.16710 \\
\hline & $\begin{array}{l}\text { Equal } \\
\text { variances } \\
\text { not } \\
\text { assumed }\end{array}$ & & & -2.221 & 10.090 & .050 & -7.84127 & 3.52979 & -15.69666 & .01412 \\
\hline
\end{tabular}

Faaliyet Süresi Hipotez Testi

H0: Şirket faaliyet süresi grupları arasında iç kontrol sistemi puanları açısından fark yoktur.

H1: Şirket faaliyet süresi gruplarının en az biri iç kontrol sistemi puanları açısından farklı1ık gösterir. 
Hal İşletmelerinin İç Kontrol Sistemi ve Sektörel Sorunları: Edirne ve Çanakkale'de Bir Alan Araştırması

Tablo 13: Levene Testi

\begin{tabular}{|c|c|c|c|c|c|}
\hline \multicolumn{4}{|l|}{ ickontrolpuani } & & \\
\hline LeveneStatistic & $d f 1$ & $\mathrm{df} 2$ & Sig- & & \\
\hline .659 & 3 & 68 & .580 & & \\
\hline \multicolumn{6}{|l|}{ ANOVA } \\
\hline \multicolumn{6}{|l|}{ ickontrolpuan1 } \\
\hline & \multicolumn{2}{|l|}{ Sumof } & \multicolumn{3}{|l|}{ MeanSquar } \\
\hline & Squares & Df & e & $\mathbf{F}$ & Sig- \\
\hline $\begin{array}{l}\text { BetweenGroup } \\
\text { s }\end{array}$ & 449.919 & 3 & 149.973 & 1.607 & -196 \\
\hline WithinGroups & 6345.067 & 68 & 93.310 & & \\
\hline Total & 6794.986 & 71 & & & \\
\hline
\end{tabular}

Levene testinin $\mathrm{p}$-değeri $0,580>0,05$ olduğundan grup varyansları homojendir. ANOVA'nın p-değeri $0,196>0,05$ olduğu için H0 hipotezi reddedilemez. Diğer ifadeyle şirket faaliyet sürelerine göre iç kontrol sistemi puanları arasında farklılık yoktur. Faaliyet sürelerine göre grupların iç kontrol puanı ortalamaları ise Tablo.13 'de verilmiştir. Buna göre işletmelerinin faaliyet sürelerinin iç kontrol sistemine etkisinin olmadığını söyleyebiliriz.

Şirketlerin Hukuki Yapıları Hipotez Testi

H0: Limited şirketlerinin iç kontrol puanlarının ortalaması ile şahıs işletmelerinin iç kontrol puanı ortalaması arasında fark yoktur.

H1:Limited şirketlerinin iç kontrol puanlarının ortalaması ile şahıs işletmelerinin iç kontrol puanı ortalaması arasında fark vardır.

Levene testinin p-değeri $(0,440)>0,05$ olduğundan grup varyansları homojendir. Bu yüzden test tablosunun üst satırındaki p-değerine bakarak hipotez sinanır. T-testinin p-değeri $0,000<0,05$ olduğundan $\mathrm{H} 0$ hipotezi reddedilir. Diğer ifadeyle, limited şirketlerin iç kontrol puanı ortalaması, şahıs firmalarının iç kontrol puanı ortalaması ile aynı değildir. Puanlarının aritmetik ortalamalarına baktığımız zaman ise limited şirketlerin iç kontrol sistemi puanının daha yüksek olduğunu görmekteyiz.

Tablo 14: Hukuki Yapı İle İç Kontrol Puanları Arasındaki İlişki

\begin{tabular}{|c|c|c|c|c|c|}
\hline \multicolumn{6}{|l|}{ GroupStatistics } \\
\hline \multicolumn{2}{|c|}{ Şirketin Hukuki Yapıs1 } & $\mathrm{N}$ & Mean & Std Deviation & $\begin{array}{l}\text { Std. } \\
\text { ErrorMean }\end{array}$ \\
\hline \multirow[t]{2}{*}{ ickontrolpuan } & Ltd Şti & 20 & 64.7500 & 8.17490 & 1.82796 \\
\hline & Diğer & 51 & 51.9804 & 7.45517 & 1.04393 \\
\hline
\end{tabular}


Tablo 15: Şirketlerin Hukuki Yapısına Göre Iç̧ Kontrol Puanlarının

\begin{tabular}{|c|c|c|c|c|c|c|c|c|c|c|}
\hline \multicolumn{11}{|c|}{$\begin{array}{c}\text { Karşılaştırılmasına İlişkin t-Testi } \\
\text { Independent Samples Test }\end{array}$} \\
\hline & & $\begin{array}{l}\text { Levene } \\
\text { for Equ } \\
\text { Varia }\end{array}$ & $\begin{array}{l}\text { S Test } \\
\text { lity of } \\
\text { aces }\end{array}$ & \multicolumn{7}{|c|}{ t-test for Equality of Means } \\
\hline & & \multirow[b]{2}{*}{$\mathrm{F}$} & \multirow[b]{2}{*}{ Sig. } & \multirow[b]{2}{*}{$\mathrm{t}$} & \multirow[b]{2}{*}{ df } & \multirow{2}{*}{$\begin{array}{l}\text { Sig. }(2- \\
\text { tailed) }\end{array}$} & \multirow{2}{*}{$\begin{array}{c}\text { Mean } \\
\text { Difference }\end{array}$} & \multirow{2}{*}{$\begin{array}{l}\text { Std. Error } \\
\text { Difference }\end{array}$} & \multicolumn{2}{|c|}{$\begin{array}{l}95 \% \text { Confidence } \\
\text { Interval of the } \\
\text { Difference }\end{array}$} \\
\hline & & & & & & & & & Lower & Upper \\
\hline \multirow[t]{3}{*}{ ickontrolpuan1 } & Equal & & & & & & & & & \\
\hline & $\begin{array}{l}\text { variances } \\
\text { assumed }\end{array}$ & .604 & .440 & 6.318 & 69 & .000 & 12.76961 & 2.02099 & 8.73784 & 16.80137 \\
\hline & $\begin{array}{l}\text { Equal } \\
\text { variances } \\
\text { not } \\
\text { assumed }\end{array}$ & & & 6.066 & 32.116 & .000 & 12.76961 & 2.10505 & 8.48237 & 17.05685 \\
\hline
\end{tabular}
Sonuçları

3.8.Yarı Yapılandırılmış Görüşme Sonucu Elde Edilen Bulgular ve

Araştırmanın ikinci kısmında; Edirne ve Çanakkale Ticaret ve Sanayi Odalarına kayıtlı 105 sebze meyve ticareti yapan işletme içinden Edirne'de 38 işletme, Çanakkale'de 35 işletme ile görüşülmüştür. Görüşme yapılan işletmelerin \% 47,9 Çanakkale ili ve ilçelerinde \% 52,1'i Edirne ili ve ilçelerinde faaliyet göstermektedir. İşletmelere sorulan sorular ve elde edilen bulgular aşağıda özetlenmiştir.

İlk soru olarak işletmelerin hal komisyonculuğu veya tüccar sıfatı seçmelerinin nedeni sorulmuştur. Katılımcıların \% 90,4'ü yeni yasa ile tüccarlığı tercih ettiklerini \% 9,6's1 da komisyonculuğu tercih ettiklerini ifade etmişlerdir. Katılımcılar, yeni hal yasasının komisyoncuların stoklama yaparak tekel oluşturulmalarını engellediğini ve komisyoncuların aldığı payın ürünün satış fiyatının yüzde 8'ini geçmeme sınırı konulmasından dolayı tüccar olarak çalışmayı seçtiklerini belirtmişlerdir. İkinci soru olarak kurumsal zincir marketlerin hallerde faaliyet göstermelerinin nedenleri sorulmuştur. Katılımcılar, yeni hal yasası ile marketlerin halde işletme açabildiklerini ve bu işletme aracılığıyla ürünleri doğrudan üreticiden alabildiklerini belirtmişlerdir. Ayrıca katılımcılar bu ürünlerin konsinye usulü ile marketlerde sattıkları için giderlerini düşürdüklerini ifade etmişlerdir. Üçüncü soru olarak hal kayıt sisteminin kayıt dışılığı önlemedeki rolü sorulmuştur. Katılımcılar, sebze ve meyve alım, satım işlemlerinin toptancı haline girmeden yapılabildiğini, ürünlerin özellikle yerel pazarlarda künyesiz olarak satılabildiğini ve bu konu ile ilgili yeterince denetimin olmadığını belirtmişlerdir. $\mathrm{Bu}$ durumun toptancı halinde faaliyet gösteren işletmeler için haksız rekabet yarattığını ifade etmişlerdir. Dördüncü soru olarak sistemdeki aksaklıkların neler olduğu sorulmuştur. Katılımcılar, süreçte yaşanılan en önemli sorunun halde faaliyet gösteren bazı işletmelerin üreticiden aldıkları ürünün rüsum bedelinin 5 gün içinde ödememelerine rağmen, ürünün künyesini alabildiklerini ve bununla ilgili bir yaptırımın olmadığını ifade 
etmişlerdir. Beşinci soru olarak katılımcılara sebze ve meyveyi üreticiden satın alma şekli sorulmuştur. Katılımcılar, sebze ve meyveyi ya üretildikten sonra ya da riski dağıtmak ve maliyetleri düşürmek için tarladan doğruda satın aldıklarını ifade etmişlerdir.

İşletmelerle yaptığımız görüşmede yukarıda belirtilen konular dışında sorunlar tespit edilmiştir. Bu sorunlarından biri Çanakkale ili Bayramiç ilçesindeki toptancı haline kayıtlı işletmelerinin \% 80'nin sadece künye almak amacıyla burada faaliyette bulundukları belirlenmiştir. Bu durum büyük şehirlerdeki toptancı hallerinde iş yeri kiralarının yüksek olmasından kaynaklanmaktadır. Sorunlardan diğeri ise, Türkiye gündeminde sürekli tartışma konusu olan ürünün tarladaki fiyatı ile satış fiyatı arasındaki farktır. Bu duruma neden olan maliyetler; rüsum giderleri, komisyon giderleri, taşıma giderleri, işçilik giderleri, ambalajlama giderleri, ürün analiz giderleri, depolama giderleri ve rafta meydana gelen fire giderleri ifade edilmektedir. Ayrıca bu fiyat farklılığının sebebi olarak büyük ölçekli işletmelerin hem üreticiden hem de toptancı hallerinden yüksek miktarda mal alımı yaparak, pazardaki arz talep dengesini belirleyebildikleri belirtilmektedir.

\section{Sonuç ve Öneriler}

Araştırmanın amacı Edirne ve Çanakkale ili hal işletmelerinin iç kontrol sistemlerinin test edilmesi ve hal işletmelerinin sorunlarının tespit edilmesidir. $\mathrm{Bu}$ amaç doğrultusunda araştırma anket ve yarı yapılandırılmış görüşme olmak üzere iki kısımda yürütülmüştür. Araştırmanın birinci kısımda elde edilen bulguların değerlendirilmesi aşağıda açıklanmıştır.

İşletmelerde eğitim düzeyi arttıkça iç kontrol etkinliğinin arttığı, daha fazla personel çalıştıran işletmelerin iç kontrol puanının daha yüksek olduğu; şirket faaliyet sürelerine göre iç kontrol sistemi puanları arasında farklılık olmadığı, şirketlerin hukuki yapılarına baktığımızda ise sermaye şirketlerinin iç kontrol sistemi puanının daha yüksek olduğunu görülmüştür. Ayrıca işletmelerde “ görevler ayrılı̆̆ı" ilkesine yeterince dikkatte alınmadığı, süreçlerin yönetiminde fatura, irsaliye gibi yasal evraklar dışında evrak kullanılmadığı, hile ve usulsüzlükleri engelleyecek yeterli bir sistemin oluşturulmadığı, fire oranlarını dikkate alan işletme sayılarının az olduğu tespit edilmiştir. Çalışmada, katılımcıların önemli bir kısmının (\% 63) yeni hal yasasının kayıt dışılı̆̆ı engellemediğini düşünmesi, sisteme olan güvensizliği ortaya koymaktadır. $\mathrm{Bu}$ sorunların çözümü için işletmelerde etkin iç kontrol sistemi kurulmalı veya var olan sistemin etkinliği test edilmelidir.

Araştırmanın ikinci kısımda elde edilen bulguların değerlendirilmesi aşağıda açıklanmıştır:

- Sebze ve meyvenin toptancı haline girişi yapılmadan, künyesiz olarak satışının yapılabilmesi,

- Hal içinde ve dişında yeterli düzeyde denetimin olmaması,

- Rüsum bedelinin ödenmesi ile ilgili sorunlar, 
- Büyük ölçekli sebze ve meyve ticareti yapan işletmelerin piyasadaki ürün fiyatlarını belirleyebilmesi.

Yeni hal yasası ekonomik ve sosyal fayda sağlamak amacıyla önemli düzenlemeleri içermesine rağmen, sistemde denetim mekanizmasının etkin çalışmamasına bağlı olarak bu sorunlar devam etmektedir. Bu bağlamda, sebze ve meyve üreticileri, tüccarlar/ komisyoncular ve hal işletmelerinin bağlı olduğu belediyelerin müteselsil sorumluluk aldığ 1 ve Bakanlık tarafindan denetimlerin daha etkin olduğu bir mekanizmanın oluşturulması ile kayıt dışıyla mücadele edilebilinir. Bu şekilde bir denetim mekanizmasının oluşturulması ile toptancı halinde faaliyet gösteren işletmeler süreçlerinin daha etkin yönetebileceklerdir.

\section{Kaynaklar}

Adanacioğlu, H ve Yercan, M. (2012). "Yeni hal Kanununun Tarım Kesiminde Olan Muhtemel Etkilerinin Değerlendirilmesi"10.Ulusal Tarım Ekonomisi Kongresi,Konya, ss.845-847.

Aksoy, T.(2005).“Ulusal ve Uluslararası Düzenlemeler bağlamında İç Kontrol ve İç Kontrol Gerekliliği:Analitik İnceleme”,Mali Çözüm Dergisi,72,ss.139.

Akyel, R. (2010). "Türkiye'de İç Kontrol Kavramı, Unsurları ve Etkinliğinin Değerlendirilmesi”, Yönetim ve Ekonomi Dergisi, 1(17),ss. 86.

Atmaca, M. (2012). "Muhasebe Skandallarının Önlenmesinde İçKontrol Sisteminin Etkinleştirilmesi”, Afyon Kocatepe Üniversitesi İ̈BF Dergisi, 14(1),ss.198.

Baskıcı, Ç., (2015).“ Kurumsal Yönetim Uygulamalarında İç Kontrol Sisteminin Önemi: Borsa İstanbul Şirketleri Üzerine Bir Araştırma", Uluslararası Yönetim İktisat ve Işsletme Dergisi, 11(25),ss. 167.

Ceyhan, İ. ve Apan, M. (2014), “COSO İç Kontrol Modeli’nin Yapısal Eşitlik Modeli ile İncelenmesi: Bir Hastane Uygulaması", Mehmet Akif Ersoy Üniversitesi Sosyal Bilimler Dergisi,5(10),ss.182.

Creswell, J. W. (2003). Researchdesign: Qualitative, quantitative, andmixed methodsapproaches (2nd ed.). ThousandOaks, CA: Sage.

Creswell, J. W. (2006)Understanding Mixed MethodsResearch, (Chapter 1). http://www.sagepub.com/upm-data/10981_Chapter_1.pdf (08.11.2018)

Çetin, B. (2009). Yeni Perakendecilik Sisteminde Toptancı Hallerinin İzlemesi Gereken Stratejileri. İstanbul Ticaret Odas1 Yayınları, No:200944, İstanbul.

Gönen, S. (2009). “İç Kontrol Sisteminin Unsurlarından Kontrol Ortamının İncelenmesine Yönelik Bir Araştırma", Muhasebe Bilim Dünyası Dergisi, 11(1),ss.182-200.

Güney, S. ve Sarı, S. (2015). "Muhasebe Denetiminin Etkinliğini Sağlamada İç Kontrolün Rolü”, Siirt Üniversitesi Sosyal Bilimler Dergisi, Sayı: 5, ss. $62-80$. 
Hal Işsletmelerinin İ̧̧ Kontrol Sistemi ve Sektörel Sorunları: Edirne ve Çanakkale'de Bir Alan Araştırması

Hatunoğlu, Z, Koca, N.ve Kıllı, M. (2012).“İç Kontrolün Muhasebe Sistemindeki Hata Ve Hilelerin Önlenmesindeki Rolü Üzerine Bir Alan Çalışması", Mustafa Kemal Üniversitesi Dergisi, 9(9),ss.173.

İbiş, C. ve Çatıkkaş, Ö, (2012), "İşletmelerde İç Kontrol Sistemine Genel Bakış", Saylştay Dergisi, 85,ss.98-99.

Kazan, K. ve Kazan, S. (2016).“ Internal Control andCompliance- Control As EffectiveMethonds of Management, DetectionandPrevention of Financial StatementFraud", Academy of Strategic Management Journal, 1(5),ss.255256.

Kızılboğa, R.ve Özşahin, F.(2013). "Etkin Bir İç Kontrol Sisteminin İç Denetim Faaliyetine ve İç Denetçilere Katkısı", Niğde Üniversitesi IIIBF Dergisi, 6(2), ss.221-223.

Ömürbek, V. ve Altay, S.(2011).” Turizm İşletmelerinde İç Kontrol Sisteminin Etkinliğinin İncelenmesi ve Manavgat Bölgesindeki Beş Yıldızlı Otellerde Bir Araştırma", Süleyman Demirel Üniversitesi İktisadi ve İdari Bilimler Fakültesi Dergisi, 16 (1), ss.383-388.

Şaşmaz, E. ve Çiftçi, Y.(2017). "İşletmelerde İç Kontrol Sisteminin Etkinliğinin Sağlanması: Mermer Sektöründe Bir İşletme Uygulaması”, International Journal of Academic Value Studies, 3(9), ss.113.

Topçu, M. (2013).'Kamuda İç Kontrol Sisteminin Coso Modeli Bağlamında Taşrada Uygulanabilirliği: İhalelerde Uygulanmasına Yönelik İki Vaka Analizi, Sayıştay Dergisi, 91, ss.10.

5957 sayılı Sebze ve Meyveler İle Yeterli Arz ve Talep Derinliği Bulunan Diğer Malların Ticaretinin Düzenlenmesi Hakkında Kanun, 26.03.2010 Tarih, 27533 Sayıl1 Resmi Gazete.

Sebze ve Meyve Ticareti ve Toptancı Halleri Hakkında Yönetmelik, 07.07.2012 Tarih, 28346 say1lı Resmi Gazete.

The 2013 COSO Framework \& SOX Compliance: https://www.coso.org/docum Ents//COSO $\% 20 \mathrm{McNallyTransition} \% 20$ Artiçle- Final $\% 20 \mathrm{COSO} \% 20 \mathrm{~V}$

ersion\%\%20Proof_5-31-13.pdf(erişim :17.08.2018)

https:www.coso.org, (erişim: 10.02.2017).

https://www.coso.org/Pages/aboutus.aspx (erişim: 01.11.2018)

www.tusiad.org.tr./yapisal-sorunlar-perspektifinde-gıda-enflasyonu-pdf (erişim 09.05.2019).

www.deloitte.com,Alpman, Gökhan,'İ̧̧ Kontrol Sisteminin Etkinliğinin Sağlanması", http://, (erişim: 10.02.2016).

www.ibb.gov.tr/sites/haller/HaberResimleri/552.doc. (erişim: 04.10.2018)

https://hks.hal.gov.tr/Media/Documents/HKSKullan.pdf( erişim:01.11.2018)

https://www.mevzuatdergisi.com/2006/12a/02.htm (erişim: 09.11.2018) 